\title{
Hong Kong-Zhuhai-Macau Bridge - An Infrastructural Marvel but?
}

\author{
Pooja Gupta, Ravi Kumar, Kritika Narayan, Karan Champaneri
}

\begin{abstract}
Hong Kong Zhuhai Macau Bridge (HZMB) is believed to be an infrastructure wonder. It is the longest sea bridge in the world which connects Hong Kong with Macau and mainland China. The bridge is seen as an omen of economic boom in the Pearl River Delta, but it brings its own environmental and other challenges to the area also. The congestion in the area is supposed to get worse and so is the air pollution in the city. The big question for local Hong Kong residents is whether the Bridge is worth the cost that has been paid for it. The case has the following objectives:

- $\quad$ To provide a context in which the student will look at the political symbolism and economic benefits of large infrastructure projects

- $\quad$ To illustrate that, in order to get some kind of economic benefit, the problems that may emerge both related to environment and people

- To provide a comprehensive insight into the cost benefit analysis of an infrastructure project.
\end{abstract}

Keywords- Infrastructure, Financing, sustainability, cost benefit analysis.

\section{INTRODUCTION}

"The world's longest sea bridge is now officially open for traffic in China. It took almost a decade to build the Hong Kong-Zhuhai-Macau Bridge (HZMB)", said CBS News correspondent Ben Tracy.

"It's meaningless for normal Hong Kongers. We rarely go to mainland China," island resident Rebecca Ko said.

"They still need it as a political symbol or icon to remind Hong Kong people... that you are connected to the motherland, with this very grand bridge," Hong Kong politician Claudia Mo said.

The above statements were made on the news segment on American news channel CBS on the day the Hong Kong Zhuhai Macau Bridge (HZMB) opened on 18 October 2018(1). The above statements give an indication that Hong Kong residents are not as enamored with the bridge as their Chinese counterparts.

Revised Manuscript Received on September 10, 2019.

Pooja Gupta, Assistant Professor, Symbiosis Institute of Business Management- Bengaluru, Symbiosis International (Deemed University) Bengaluru, Karnataka,India.

(Email: poojagupta@sibm.edu.in)

Ravi Kumar, Adjunct Faculty, Symbiosis Institute of Business Management- Bengaluru, Symbiosis International (Deemed University) Bengaluru, Karnataka India.

(Email: ravi.kumar@sibm.edu.in)

Kritika Narayan, Student Research Associate, Symbiosis Institute of Business Management- Bengaluru, Symbiosis International (Deemed University) Bengaluru, Karnataka, India.

(Email: kritika.narayan19@sibm.edu.in)

Karan Champaneri, Student Research Associate, Symbiosis Institute of Business Management- Bengaluru, Symbiosis International (Deemed University)Bengaluru, Karnataka, India.

(Email: karan.champaneri19@sibm.edu.in)
The official inauguration of the HZM Bridge was considered as a feather in the cap for China and its government headed by Xi Jinping. The bridge at the time was the most challenging and costliest infrastructure projects in the world. The bridge traverses China's Pearl River Delta, connecting Hong Kong, the resort city of Macau and nine cities in southern Mainland China with a population of around 70 million people.

The bridge is considered to be an infrastructural wonder. The construction of the bridge required more than 400,000 tons of steel. Two artificial islands had to be built to facilitate the commercial ships through the busy seaway.

\section{HISTORY OF CHINA AND HONG KONG}

Hong Kong became a colony of the British empire after the first Opium war in 1842. After the area was extended, in 1898, Britain obtained a 99-year lease on the whole Hong Kong Peninsula. As per the lease agreement, Britain returned the entire territory to China at the end of the lease period in 1997. China pledged to grant a Special Administrative Region status to Hong Kong with its governance and economic systems separate from those of mainland China (2).

Since the handover of the territory back to China, the relationship between China and Hong Kong has been guarded. Hong Kong natives do not feel the same affiliation to China and feel that Beijing tries to force policies on them (3).

Hong Kong has its own constitution which gives a set of civil liberties to its citizens. This constitution is different from that of Mainland China and has been a major bone of contention between the two. The citizens of Hong Kong believe that Beijing is trying to influence the Legislative Council of Hong Kong to revamp the economic and civil policies in favor of China.

Chinese government has projected the Hong Kong-ZhuaiMacau Bridge as a road to prosperity for the entire peninsula whereas the sceptics of the project see it as an underhanded way of the Chinese government to integrate Hong Kong with mainland China without any major need of the project.

From the viewpoint of a study of infrastructural development in the socio-economic development of regions, to an observer, this offers an interesting experiment in the attempt at the integration of three different regions with (a) different set of Institutions and (b) Very different history and cultures. 
Also interesting is the fact that the three cities in question are those with different political systems, traffic rules and road capacities and differing environmental demands.

\section{CONCEPTION OF THE PROJECT}

Since the 1980's the Chinese Government had prioritized linking up the three provinces of Hong Kong, Macau and Guangdong. The development towards the HMZ bridge project occurred over three stages. Firstly, the transportation links between Hong Kong and Macau with mainland China were developed. Secondly, a road transport network between Hong Kong and the Guangdong region was established. This resulted in significant expansion of the economic growth between these two specific regions. However, the third stage of the overall development plan of the 1980's did not fructify as the sea links between Hong Kong and the western bank of the Pearl River Delta Region did not come to being and therefore the transportation link between these two important regions was a missing link in the masterplan and continued to remain so till the development of the HMZ bridge $(4,5,6)$.

In the aftermath of the shock of the Asian Financial Crisis of 1997, the response of the Chinese Government was to invigorate its economy. The Hong Kong government too laid emphasis on building a sea link or an all sea route that would connect it with Macau and Zhuhai city of Guangdong province. This, it was hoped, would capitalize on the advantages Hong Kong enjoyed as a port of International repute apart from it being at the crossroads of Global trade.

Thus, the imperative need to link the three regions was recognized by the Government in China, which would satisfy the growth objectives outlined above. Following extensive research by the National Development and Reform Commission of China, the creation and established of a physical link, a bridge between Hong Kong Macau and Zhuhai (HMZ) was considered feasible both from an economic and political standpoint (7).

Therefore, in March 2004 an Administrative Office of the HMZ bridge, Advanced Works Coordination Group (AWCG) was set up. After extensive reviews in December 2006 , the actual construction of the bridge commenced from 2009.

\section{SIGNIFICANCE OF THE BRIDGE}

From the traditional three hours taken to transit from Hong Kong to Zhuhai, the bridge was designed to cut the travel time to 30 minutes. The bridge would effectively transform the Chinese economic Growth model from that of the development of super-cities to that of city clusters. In parallel to the HMZ bridge project, the Guangdong province had in place a plan to quadruple the rail network within the cities in its region by the year 2030(8).

Coupling the benefits of HMZB with this rail network plan would add to the overall benefits manifold in terms of the development of big city clusters. The other major benefits were in the reduction of over-population in the hub cities and the use of the urban railway network would ease congestion on roads apart from the multiple savings on pollution caused by the vehicles. It was estimated that the GDP of the city cluster hub covered by the HMZB which

was US\$1.38 trillion in 2010 would compound to US $\$ 4.62$ trillion by the year 2030(9.10). To provide a comparison, the 2030 GDP number would exceed the GDP of the UK and separately, also the sum of output from the metropolitan areas of Tokyo, New York and San Francisco combined. Historical studies have shown that the rising populations of Tokyo, New York and San Francisco metropolitan regions were mainly due to inflows from satellite cities, which were driven largely by better infrastructure connecting the hub cities with its satellites. This trend was also aided by favorable governmental policies.

The primary risk to the plan laid out by the AWCG were possible coordination problems between the local governments of the HMZ region, which also include changes in property policies in the area apart from changes to the priorities of the central government in China. Given the experiences in the development of city clusters in the USA and in Japan, smaller satellite cities benefit enormously from better transportation networks with higher property prices in hub cities encouraging residents out of hub cities into satellite cities, aided by efficient transportation networks. Government policies that incentivize the location of industries in these areas via land acquisition, labor laws and in cheaper acquisition of capital also aid in the development of city clusters.

The pre-eminence of economic growth of the Hong Kong region is well established. It drew its strength largely as it being a center of finance, shipping and commercial activity. This has had a positive bearing on adjoining regions namely Macau (largely tourism) and in parts of Mainland China (as a source of manufacturing outsourcing). Hong Kong has also benefited and was also dependent on the bountiful natural resources of the adjoining regions. Thus, the relationship that the City State of Hong Kong enjoyed was symbiotic with its neighboring regions of China. These reasons alone account for the dominance of Hong Kong as the geography with a high level of exports.

The mainstays of Macau's economy have been Tourism, insurance and in Finance. The historically established distribution of industries and the civil arrangements between Hong Kong and Macau had encouraged and cemented the long abiding link between the economies and cultures of the two regions.

Thus, the economic aspirations of the three regions were met to a great extent by the conceptualization and eventual fructification of the HMZ bridge. The economic effect of Hong Kong and its augmentation with the economic abilities of the cities Macau and Zhuhai would result in the growth of the GDP of each of these regions as per the estimates (quadrupling of existing output of goods and services from the combined region).

\section{HMZB AUTHORITY}

This was to be collectively managed by the Governments of Hong Kong semi-autonomous region, Macau and Guangdong. It was tasked with the development, initiate transactions and also with the ecological conservation 
challenges of the project. Under the umbrella of "One Country, two systems" adopted by the Chinese government, the HMZB would be a pioneering effort in collective advancement of a city cluster by the respective Governments (11).

The vision handed down to the Authority was to "construct a first-class sea crossing channel, which will provide high quality service and serve as a landmark".

Thus, the authority would initiate the project by a bottomup approach with a holistic objective of boosting the transit, economy and the cultural interaction between the three distinct regions. It was expected to do so by putting in place an objective bureaucratic ethos and execute the project in a transparent manner with high standards of efficiency (12).

\section{FINANCING OF THE HMZB \& RESULTS}

According to the HMZB authority the total cost of the bridge was US $\$ 7.56$ billion

Contributions from the respective Governments were as follows (population figures are also included to provide a comparison)

Source: Created by the authors

\begin{tabular}{|l|c|c|}
\hline City & Contribution & Population \\
\hline Hong Kong & $\$ 1.38$ billion, & $\begin{array}{c}\text { population of } \\
7.35 \text { million }\end{array}$ \\
\hline Zhuhai/China & $\$ 1.43$ billion & $\begin{array}{c}\text { population of } \\
1.68 \text { million }\end{array}$ \\
\hline Macau & $\$ 0.43$ billion & $\begin{array}{c}\text { population of } \\
0.61 \text { million }\end{array}$ \\
\hline $\begin{array}{c}\text { Bank } \\
\text { Loans(syndicated) }\end{array}$ & $\$ 4.32$ billion & \\
\hline TOTAL & $\$ 7.56$ billion & \\
\hline
\end{tabular}

Data from the Hong Kong Transport and Housing Bureau shows that the city-state spent an additional US $\$ 4.57$ billion on its boundary crossing facilities US $\$ 3.19$ billion on the construction of a road link between the main bridge to its boundary crossing. Thus, the total contribution of Hong Kong is around US\$9 billion, which has been funded by its taxpayers.

\section{CONTENTIONS AGAINST AND FOR THE PROJECT}

HZMB project was proclaimed as the messiah for the economy of the Pearl River Delta area but at the same time it also raised a lot of concerns $(13,14)$.

\section{Effect on the Fisheries Industry of the Delta area}

One of the major impacts of the bridge was believed to be on the fishery industry in the Delta region. The construction of the bridge and subsequent usage could lead to potential damage of the fishing grounds and the fisheries. During the long period of the construction of the bridge, local fishermen made numerous claims that their work got affected due to the bridge and also the construction was leading to a loss of marine ecosystem.

\section{Chinese white dolphins}

The environmental groups were worried about the impact on the marine ecosystem. It was found that endangered Chinese white Dolphins had decreased in numbers as a direct impact of the construction of the bridge in their nesting waters.

\section{Expected Air and Noise Pollution}

The opening of the bridge is expected to increase the traffic at least threefold in the Pearl River Delta area. This would give rise to increased air and noise pollution.

\section{Surge in House Prices}

The construction of the bridge has led to a dramatic increase in housing prices by more than five times in the area. This has made the life difficult for the current residents as housing in the area is becoming unaffordable for them.

\section{Benefits of $H Z M B$}

The construction of the bridge is not just a gloomy picture. It has had certain benefits also. The construction of the bridge has provided employment to thousands of workers. The employment is expected to surge with the opening of the bridge which is expected to bring more investments and thus more employment opportunities in the Pearl River Delta area.

Hong Kong is a developed economy. The Chinese government believes that linking of Hong Kong physically to the less developed parts of the Pearl River Delta would lead to an investment and opportunity flow in the right direction. Hong Kong is seen as a cash rich but land poor whereas Zhuhai area is seen as land rich but investment poor. The bridge is seen as a connector of investments from Hong Kong to cheap labor and cheap real estate in the Zhuhai area $(15,16)$.

The benefits listed out by the Chinese government seem to be more tilted in the favor of Mainland China. The cost of the bridge is borne to a larger extent by the Hong Kong residents. Thus, it is a dilemma for every ordinary Hong Kong resident as to whether the HZM Bridge is good for them or not.

\section{TEACHING NOTE}

This is a teaching case and following are the objectives of the case:

Teaching Objectives

- $\quad$ To provide a context in which the student will look at the political symbolism and economic benefits of large infrastructure projects

- To illustrate that, in order to get some kind of economic benefit, the problems that may emerge both related to environment and people

- To provide a comprehensive insight into the cost benefit analysis of an infrastructure project the following points can be used by the instructor while taking the case in the class. 


\section{POLITICAL SYMBOLISM OF THE BRIDGE}

The instructor can start the discussion in the class by first talking about the specifics of the bridge. He can ask students to highlight the features of the bridge and expand on their symbolism. It is the longest sea bridge in the world. It links Hong Kong to Macau and to Zhuhai in mainland China; it is the most arduous engineering projects ever built. It is more than just constructing the bridge; it is about tying Hong Kong into the mainland and advancing the evolution of southern China. Xi Jinping has an ambitious plan to mutate this part of China into a greater Bay Area. This is the third phase of economic expansion alongside Beijing and Shanghai. The Bay Area already has three of the world's top ten ports and three of Asia's busiest airports. There will be amendments to relax the movement of people goods and capital across the border (17).

The aim of the bridge is also to attract entrepreneurs. The economic links between the Bay Area cities go back several decades but further integration has been limited by Beijing's capital controls the great internet firewall and travel restrictions.

\section{IMPACT ON PEARL RIVER DELTA}

The instructor can ask the students to list down the economic benefits of the bridge and then discuss each point in detail.

The bridge will prove to be beneficial for foreign and Hong Kong investors, making locales within three hours of Hong Kong, attractive for investment. With the bridge now open, and with the Guangzhou-Shenzhen-Hong Kong Express Rail Link operational, more investment is expected to flow westward as far as the Guangxi Zhuang autonomous region. It is also expected that businesspeople from Hong Kong will now find it easier to extend their business and trade to Mainland China $(18,19)$.

Major transport link between east and west banks of the Pearl River, would boost the stream of tourists and trade between the three major ports of Hong Kong, Macau and Mainland China. The growth forecast as a result of this bridge expects consolidation of Hong Kong as the nucleus of trading hub in the region due to easy accessibility to ports in Mainland China.

\section{Expected Environmental Effects}

The instructor can guide student's attention to the adverse impacts mentioned in the case.

- Impact on the fisheries industry

- $\quad$ Problems faced by fishermen in the estuary area

- Concern about Chinese White Dolphin

- Increased traffic congestion on entry and exit points of the bridge

- Increase in air pollution due to traffic on the bridge

The instructor may explain to the students that some of these problems are only anticipated and will accrue over a time period (20).

Swot Analysis Of The Build Operate Transfer Model Of The Bridge

The instructor, if she wants, can emphasize on the financing and construction of the bridge. The SWOT model in this case can be used to critically look at the pros and cons of financing methodology of the bridge.

Strengths:

- Promoting foreign direct investments into developing countries.

- $\quad$ Reduced stress on government for funding infrastructure projects and its recurrent expenditure.

- Both the contractors and financiers are committed to the successful completion of the project on time

- $\quad$ Project evaluation standards are kept very high Weakness:

- This model may not be suitable for all kinds of infrastructure projects

- To achieve financial feasibility, such projects generally have high tariff structures which makes them unattractive

- As money is raised internationally from different sources, foreign exchange risk is high

- The extensive legal agreements and provision of guarantees increases the project cost

Opportunities:

- Integration of new technologies in developing countries is made easier by this model

- Technology transfer in developing countries becomes easier

- Creating an opportunity for private players to grow

- Creates an inducement for capital inflows into a country

Threats:

- $\quad$ For BOT schemes, there might be several problems at the handover stage

- If the schemes are not structured properly, resources could then get depleted, which is opposite of sustainable goals of the project promoters.

- Unpredictability in politics makes investors wary about long term BOT schemes

\section{Cross Cultural Issues Between Hongkong And China}

The instructor can ask the students to enumerate the cultural differences between Hong Kong and China and find out if they affect the trade relations between the two and specifically the construction of the bridge (21).

- Culture: Since Hong Kong has experienced different colonial encounters from different generations, people in Hong Kong have developed different perspectives of their self-identities.

- The distinctiveness of Hong Kong Id comes with a need to differentiate it from the Chinese identity.

- Language: This is one of the major differences between the two with Cantonese being the primary language in Hong Kong and Mandarin being the primary language in Mainland China.

- Government: Hong Kong being a limited democracy is a Special administrative region under China. Chinese authorities consider Hong Kong as their territory but people of Hong Kong dispute the claim. 
A conclusion section is not required. Although a conclusion may review the main points of the paper, do not replicate the abstract as the conclusion. A conclusion might elaborate on the importance of the work or suggest applications and extensions.

\section{XI. " AN IMPRESSIVE BUT UNNECESSARY, MULTI-CITY BRIDGE"}

The instructor can use the following points in summing up the case. The students can be asked to give points and then the instructor sums up the discussion. Some of these points for the discussion could include:

The Hong Kong-Zhuhai-Macau Bridge is the world's longest sea bridge, but question mark is being raised on this architectural achievement since neither the actual utilization of the bridge received much enthusiasm nor the large display of the models at the Hong Kong Science Museum. The enormous and complex 18-mile sea bridge with a 4mile underwater sea tunnel (and artificial island entrances), had the project run two years behind schedule with $\$ 1.5$ billion over budget. But the scandalous connections of the project have made many question its existence, if this bridge has been built by the quasi-democratic Hong Kong government just to be added in their list of unnecessary projects to show their accomplishments.

The bridge has been built with the intension to shorten the travel time between three very different places: Hong Kong, a former British colony and international finance hub of 7.3 million; Macau, a former Portuguese colony that is minuscule in size but dwarfs Las Vegas in gambling revenue; and Zhuhai, a mainland city with a population of 1.6 million. But is the Bridge's purpose justified to connect three already very connected places. Additionally, the lengthy set of rules does not make it easy for an average Hongkong resident to use the bridge and drive from end to end. Notably, public excitement is fading away even further as another rival bridge on the Pearl River Delta also nears completion. According to South China Morning Post, ahead of the bridge's opening the traffic predictions were down by as much as 26 percent.

\section{EPILOGUE}

The bridge was inaugurated on 24th October 2018. As of now, it has surpassed its expectations in terms of number of people crossing the bridge. But there have been some unforeseen problems also. There was a huge influx of tourists coming to Hongkong from Mainland China. So barely after a month of operations, the authorities had to put various measures in place to restrict the entry of tourists through the bridge.

There seem to be lot of problems that local authorities seem to be struggling with - surge in crowds, surge in parking, allotting space for vendors, overselling of tickets on shuttles. It will take some time to determine if the HZMB is really a success or a failure.

\section{REFERENCES}

1. https://www.cbsnews.com/news/hong-kong-zhuhaimacau-bridge-opens-critics-view-as-china-tighteninggrip/ retrieved on 23rd February 2019

2. Scott, I. (1989). Political change and the crisis of legitimacy in Hong Kong. University of Hawaii Press.

3. https://freedomhouse.org/report/freedomworld/2018/hong-kong - retrieved on December 13, 2018

4. http://www.hzmb.org/en/bencandy.asp?id=2 - Retrieved on 9th December, 2018

5. https://www.ft.com/content/43a34a48-f16e-11e8-9623d7f9881e729f - DECEMBER 3, 2018, retrieved on December 13, 2018

6. https://www.hyd.gov.hk/en/road_and_railway/hzmb_proj ects/6835th/index.html - Retrieved on 9th December, 2018

7. http://www.hzmb.hk/eng/benefits_transportation.html Retrieved on 9th December, 2018

8. http://www.hzmb.org/en/bencandy.asp?id=4 - Retrieved on 9th December, 2018

9. http://www.hzmb.org/en/bencandy.asp?id=2 - Retrieved on 10th December, 2018

10. https://www.chinadailyhk.com/articles/80/240/197/15350 41433224.html - Retrieved on 10th December, 2018

11. http://www.macaubusiness.com/macau-hzmb-sees-1-79million-passengers-in-first-month-chinese-govt/ Retrieved on 10th December, 2018

12. http://www.hzmb.hk/eng/img/overview/about_overview1 _p191.jpg - Retrieved on 10th December, 2018

13. https://www.scmp.com/news/hong-kong/healthenvironment/article/1990312/experts-blame-hong-kongzhuhai-macau-bridge - Saturday, 16 July, 2016, retrieved on December 13, 2018

14. https://www.hongkongfp.com/2016/12/06/the-hk-zhuhaimacau-bridge-an-economic-excuse-for-a-politicalgamble/ - 6 December 2016, retrieved on December 13, 2018

15. https://www.legco.gov.hk/yr1314/english/panels/ea/papers/ea0625cb1-1648-2-e.pdf - 25 June 2014, retrieved on December 13, 2018

16. https://www.news.com.au/travel/travel-updates/worldslongest-sea-bridge-finally-opens/newsstory/e80c9182c7c905823aa92f7e41adbaf1, published on 24 October, 2018, retrieved on December 13, 2018

17. https://www.businessinsider.in/These-are-the-15-bestairports-in-the-world/articleshow/57659586.cms - March 16, 2017, retrieved on 13 December 2018

18. http://www.geopolitika.hu/en/2018/08/22/the-integrationof-the-pearl-river-delta-the-hong-kong-zhuhai-macaubridge/ published on August 22 2018, retrieved on December 132018

19. https://www.telegraph.co.uk/news/world/chinawatch/business/pearl-river-delta-bridge/ published on 28 November 2018, retrieved on December 132018

20. http://www.scmr.com/article/the_differences_between_h ong_kong_and_mainland_china published on March 06 2017, retrieved on December 132018

21. https://www.scmp.com/news/hong-kong/hong-kongeconomy/article/2174845/visitors-hong-kong-zhuhaimacau-bridge-tail-after published on November 25 , retrieved on December 13, 2018

\section{AUTHORS PROFILE}

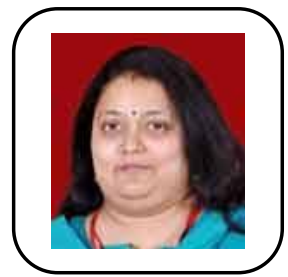

Pooja Gupta is a BA (Hons) Economics graduate from Sri Ram College of Commerce, University of Delhi. She has completed her MBA (Finance) from the International Management Institute, New Delhi. Having completed her NET (UGC), she is currently pursuing a $\mathrm{PhD}$ in the area of Behavioural Finance. She has 15 years of 
teaching experience and teaches Corporate Finance, Security Analysis, Valuation and International Business. Her research interest is in the area of Contrarian Investing and Behavioural Finance. She has presented papers in various International and National Conferences.

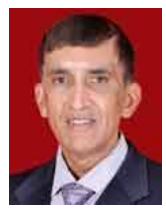

V. Ravi Kumar spent nearly 30 years in Corporate Life in the area of Banking with a specialization in the area of Financial Markets. He headed the Treasury for ICICI Bank, IDFC Bank and the ING Group in India. He began his banking career with State Bank of India. He progressed in his career as a Senior Dealer with ANZ Grindlays and Chief Dealer with ABN AMRO Bank before assuming the Head of Treasury position. He has also served on the Board of IIM Bangalore, ING Mutual Fund and with FEDAI and FIMMDA (Fixed Income Money Market and Derivatives Association), both of which are self-regulating entities established by the Govt. of India.. 